\title{
LA OBLIGACIÓN DEL ESTADO COLOMBIANO DE REPARAR LOS DAÑOS QUE SUFRE LA POBLACIÓN DESPLAZADA
}

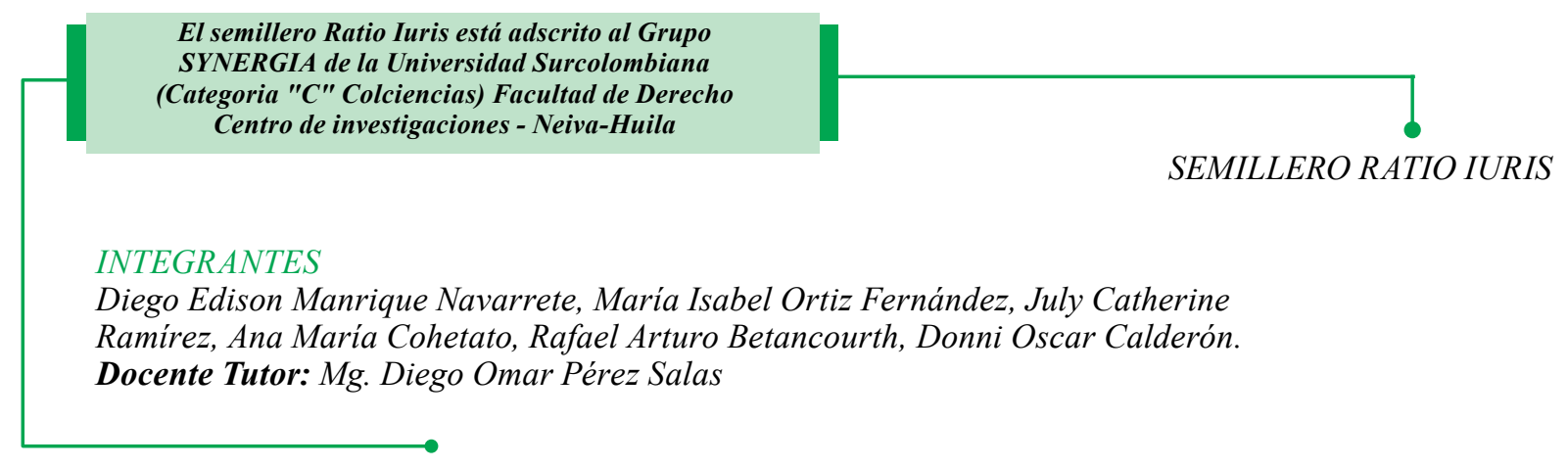

RESUMEN

El fenómeno del desplazamiento forzado representa una sistemática vulneración de la normativa, principios y valores que integran el Estado Social de Derecho, evidenciada en los múltiples daños que causa a las victimas pues las priva de todas las garantías y derechos que adquirieron por el solo hecho de ser personas, de estar adscritas a un Estado al cual se han asociado para ser precisamente garantía de sus derechos y necesidades.

Consecuencia de la trasgresión por parte del agente estatal de estos preceptos normativos y su consecuencial daño para los asociados, nace la obligación para el Estado de resarcir los daños causados.

\section{PALABRAS CLAVE}

Reparación integral, Responsabilidad del Estado, Jueces Administrativos, Corte Interamericana de Derechos Humanos, Daño Antijurídico, Justicia Transicional.

\section{ABSTRACT}

The forced moving pehnomenon represents a systematic violation of de rules, principies and values which integrate the right social state, proved in the different damages caused to the victims because it deprive them of all alquired guarantees and rights fo $r$ being people, being attached to a state which they have been associated to be a guarantee of their rights and need I as a consequence of the transgretion by the statal agent of this normative precepts and its consequencial damage to the associated, the state feels the duty of compensar the caused damage.

\section{KEY WORDS}

Integral Reparation, State Responsibility, Administrative Juidges, Human Rights Interamerican Parliament, Antijuridical Damage, Transitional Justice. 


\section{INTRODUCCIÓN}

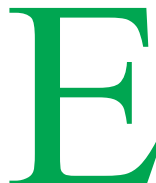
$n$ el Derecho colombiano tanto en la ley como en la jurisprudencia del Consejo de Estado, la estipulación de la obligación a cargo del Estado de reparar integralmente los daños antijurídicos sufridos por la población desplazada, es una labor reciente, tanto para el legislador como para los jueces y tribunales administrativos, a pesar de que el desplazamiento forzado ha sido un fenómeno constante en Colombia con sistemáticas violaciones de derechos humanos a las víctimas.

La investigación realizada por el semillero Ratio Iuris, cuyos resultados se plasman en el presente artículo, pretendió establecer si a la luz del derecho colombiano el Estado es responsable de reparar integralmente los daños antijurídicos sufridos por la población desplazada, lo que naturalmente implicaba un estudio del régimen de responsabilidad estatal tanto en el derecho interno como en el internacional. En cuanto a este, se analizó jurisprudencia de la Corte Interamericana de Derechos Humanos, Tribunal que en numerosos fallos ha condenado al Estado colombiano a reparar daños causados por violaciones de derechos humanos, especialmente con crímenes de lesa humanidad como desaparición forzada y desplazamiento, así como la Convención Americana de Derechos Humanos, suscrita por Colombia en la que se establecen obligaciones para los Estados parte y consecuentemente un corolario de responsabilidades por el incumplimiento de estas.

En cuanto al derecho interno el estudio se centró en jurisprudencia del Consejo de Estado la cual, sobre el tema de desplazamiento es relativamente reciente pues la primera providencia que ordenó al Estado reparar daños sufridos por desplazados data del 15 de agosto de 2007 Sección Tercera magistrado ponente Ruth Estela Correa. Así mismo fue objeto de estudio legislación marco tanto en el tema de reparación como en el de responsabilidad estatal, como la Ley 446 de
1998, el artículo 8 de la Ley 975 de 2005, los artículos $2-90$ y 6 de la Constitución Nacional, el decreto 1290 de 2008 y la Ley 1190 de 2008.

Fruto de los estudios mencionados, se obtuvieron resultados con los que se logró dar respuesta al problema de investigación, los cuales se plasman en este artículo, así como las fuentes que llevaron a la respuesta de la pregunta investigativa, los elementos de la responsabilidad y regímenes aplicables a esta clase de responsabilidad estatal.

\section{PROBLEMA DE INVESTIGACIÓN}

El desplazamiento forzoso ha sido un fenómeno constante en la realidad nacional, según datos de la Consultoría para los Derechos Humanos y el Desplazamiento (CODHES), 3.662 .842 personas han sido desplazadas por la violencia hasta el 25 de octubre de 2005 y día a día esta cifra aumenta producto de la violencia política asociada al conflicto armado interno que aqueja al país a la par de la universalización de las víctimas. Es así como las personas victimas de este flagelo han tenido que soportar una serie de daños antijurídicos que comportan una violación sistemática de derechos, normativa, principios y valores, que para el año 2007 no habían sido objeto, en el derecho interno, de ningún tipo de reparación procedente de una decisión judicial de tribunal administrativo, como tampoco de legislación alguna.

En cuanto al Derecho internacional y jurisprudencia de tribunales como la Corte Interamericana de Derechos Humanos, se tiene que en los casos en que se cometieron dentro del territorio del Estado colombiano crímenes de lesa humanidad, de los que se demandó una reparación como desaparición forzada y desplazamiento forzado. Este alto tribunal profirió condenas que obligaron al Estado a reparar a las víctimas, las cuales se presentaron por la concepción de que la responsabilidad 
internacional puede generarse por actos de violación de derechos por parte de particulares, en principio no atribuibles al Estado. Pero teniendo en cuenta que según la Corte "los Estados partes en la Convención tienen obligaciones erga omnes de respetar y hacer respetar las normas de protección y de asegurar la efectividad de los derechos allí consagrados en toda circunstancia y respecto de toda persona"'.

Esas obligaciones del Estado proyectan sus efectos más allá de la relación entre sus agentes y las personas sometidas a su jurisdicción, pues se manifiestan también en la obligación positiva del Estado de adoptar las medidas necesarias para asegurar la efectiva protección de los derechos humanos en las relaciones inter-individuales. La atribución de responsabilidad estatal por actos de particulares puede darse, según criterio de la CIDH, en casos en que el establecimiento incumple, por acción u omisión de sus agentes, cuando se encuentren en posición de garantes. Esas obligaciones erga omnes contenidas en los artículos 1.1 y 2 de la Convención Americana de Derechos Humanos, suscrita por Colombia y que es la fuente primaria de la obligación y por ende la responsabilidad estatal para el caso de violaciones de derechos humanos.

Para la CIDH "Es suficiente la demostración de que ha habido apoyo o tolerancia del poder público en la infracción de los derechos reconocidos en la Convención, u omisiones que hayan permitido la perpetración de esas violaciones" ${ }^{2}$. Es esta la conclusión de la línea jurisprudencial manejada por este tribunal Internacional, y de la que se deduce que la responsabilidad del Estado colombiano ante la comunidad internacional, es objetiva, y por tanto su obligación de reparar más imperativa.
En el derecho colombiano, "la responsabilidad estatal se fundamenta en el art. 90 constitucional, el inciso segundo del artículo 2 de la constitución, el artículo 6, así como el concepto de daño antijurídico"'. Aniveljurisprudencialen Colombia son aplicables en responsabilidad extracontractual del Estado los regímenes de falla del servicio en su modalidad de probada y presunta, de daño especial, de riesgo excepcional.

El enunciado fue el marco de responsabilidad del Estado para el año 2007, por lo que se cuestionó qué clase de reclamación por reparación podrían emprender las víctimas del desplazamiento en Colombia, si eran titulares del derecho a ser reparadas integralmente. Así se planteó la pregunta investigativa: ¿Es responsable el Estado colombiano de reparar integralmente los daños que sufre la población desplazada?, en caso afirmativo ¿En qué situaciones opera dicha responsabilidad y en qué modalidades?

\section{JUSTIFICACIÓN}

La responsabilidad del Estado colombiano de reparar integralmente los daños de las víctimas de desplazamiento, es un tema novedoso tanto para la jurisprudencia como para la doctrina colombiana. El Consejo de Estado solamente ha fallado dos casos en los que imputó al Estado responsabilidad por desplazamiento forzado, conocidos como Caso Filo Gringo y la Gabarra, en los que al respecto de la responsabilidad estatal se dijo:

“(...) A propósito de la responsabilidad del Estado por omisión, son procedentes estas breves consideraciones. El inciso segundo del artículo $2^{\circ}$ de la Constitución establece que "Las

1 Corte Interamericana de Derechos Humanos. Caso Masacre de Pueblo Bello Vs Colombia, Sentencia 31 de enero de 2006; Caso de Masacre de Mapiripán Vs Colombia, Sentencia de 15 de septiembre de 2005; Caso Masacre de la rochela Vs Colombia, Sentencia 11 de mayo de 2007; Caso Masacre Ituango Vs Colombia, Sentencia 1 de julio de 2006.

2 Corte Interamericana de Derechos Humanos. Caso Masacre de Pueblo Bello Vs Colombia, Sentencia 31 de enero de 2006, párr.. y ss; Caso de Masacre de Mapiripán Vs Colombia, Sentencia de 15 de septiembre de 2005; Caso Masacre de la Rochela Vs Colombia, Sentencia 11 de mayo de 2007.

3 República de Colombia. Consejo de Estado, Sección tercera. Sentencia 15 de agosto de 2007, expediente 401, Magistrado Ponente Ruth Stella Correa Palacio, Actor Yudy Esther Cáceres y otros. 
autoridades de la República están instituidas para proteger a todas las personas residentes en Colombia en su vida, honra, bienes, creencias y demás derechos y libertades, y para asegurar el cumplimiento de los deberes sociales del Estado y de los particulares". Por su parte, el artículo $6^{\mathrm{o}}$ ibídem establece que los servidores públicos son responsables por infringir la Constitución y las leyes y por omisión o extralimitación en el ejercicio de sus funciones." ${ }^{4}$

“(...) En relación con la responsabilidad del Estado por omisión, ha considerado la Sala que para la prosperidad de la demanda es necesario que se encuentren acreditados los siguientes requisitos: a) la existencia de una obligación legal o reglamentaria a cargo de la entidad demandada de realizar la acción con la cual se habrían evitado los perjuicios; b) la omisión de poner en funcionamiento los recursos de que se dispone para el adecuado cumplimiento del deber legal, atendidas las circunstancias particulares del caso; c) un daño antijurídico, y d) la relación causal entre la omisión y el daño." 5

El tema de la responsabilidad del Estado implica el rompimiento de paradigmas imperantes del Estado de Derecho, así como del reconocimiento de derechos universales a los ciudadanos víctimas de la autoridad militar del Estado, lo que se refleja en el régimen de responsabilidad estatal descrito que solamente admite según la jurisprudencia citada, responsabilidad en la modalidad de falla en el servicio por acción u omisión, esta última para los casos mencionados. Lo que se busca es acentuar la concepción del derecho universal a la reparación integral de las víctimas, su reconocimiento por parte del ente estatal; así como establecer el fundamento de la responsabilidad Estatal, las causales de imputación por los daños causados, dar a las víctimas y a la actividad misma de los destinatarios del derecho, los instrumentos jurídicos sustanciales que podrían desarrollar un concepto más amplio de la responsabilidad extracontractual del Estado, necesario para atender los daños que se evidencian no solo en el desplazamiento forzado sino en la universalidad de las víctimas del conflicto interno que vive el país.

\section{RESULTADOS}

\subsection{Elementos de la Responsabilidad Extracontractual del Estado}

Los elementos de la responsabilidad en el marco legal y constitucional son tres: el hecho generador a cargo de un agente estatal, el daño antijurídico y el nexo causal entre el hecho u actuación estatal y el daño. Para el derecho administrativo es también un elemento de la responsabilidad del Estado el criterio de imputación, o el daño atribuible al Estado, que opera según las circunstancias de cada caso en uno u otro régimen de responsabilidad según el criterio jurisprudencial.

Para el presente caso analizaremos lo tendiente a la responsabilidad delEstado por desplazamiento forzado, abordado el núcleo de cada elemento de acuerdo al criterio jurisprudencial del Consejo de Estado y la jurisprudencia de la Corte Interamericana de Derechos Humanos.

\section{a) Hecho Generador del Daño}

Respecto a la conducta u hecho generador, para que se configure la responsabilidad del Estado, este debe estar a cargo de un agente administrativo, como lo prescribe el art. 86 del Código Contencioso Administrativo:

"La persona interesada podrá demandar directamente la reparación del daño cuando la

4 República de Colombia, Consejo de Estado, Sección tercera. Sentencia 15 de agosto de 2007, expediente 401, Magistrado Ponente Ruth Stella Correa Palacio, Actor Yudy Esther Cáceres y otros

5 República de Colombia, Consejo de Estado, Sección tercera. Sentencia de 26 de enero de 2007, expediente 213-01, Magistrado Ponente Ruth Stella Correa Palacio, Actor Jesús vaca y otros. 
causa sea un hecho, una omisión, una operación administrativa o la ocupación temporal o permanente de inmueble por causa de trabajos públicos o por cualquiera otra causa"

Entonces en un eventual proceso contencioso de responsabilidad, esta se derivaría de los hechos u omisiones originados en una conducta administrativa los cuales deben producir un daño para que la obligación Estatal se materialice en una decisión judicial.

Respecto al hecho dañoso del operador administrativo, el Consejo de Estado ha diferenciado entre las imputaciones fácticas y jurídicas, entendidas las primeras como las indicaciones históricas referidas a los hechos en los cuales el demandante edifica sus pretensiones; o el simple señalamiento de las causas materiales, en criterio de quien imputa, que guardan inmediatez con el hecho y que, se considera, contribuyeron desde el punto de vista físico a la concreción del daño. En tanto que las segundas imputaciones, las jurídicas, aluden a la fuente normativa de deberes y de obligaciones (constitucionales, legales, administrativas, convencionales o contractuales) en las cuales se plasma el derecho de reclamación ${ }^{6}$.

Así las cosas el hecho dañoso, se constituye en las causas materiales que siguieron la producción del daño, como también la violación de normas que prescriben deberes y obligaciones que fueron incumplidas por el agente estatal. En este punto, ese hecho dañoso puede haber sido producido por un tercero, caso en el cual opera el criterio de imputación de falla en el servicio por acción cuando el agente estatal tuvo participación directa en asocio con el tercero en la producción del daño, por omisión cuando se demuestra que el agente estatal tenía conocimiento del hecho dañoso omitiendo su deber de protección.

El Consejo de Estado ha acogido la interpretación del criterio de imputación de falla en el servicio, imputando responsabilidad al Estado por desplazamiento forzado en dos fallos ya mencionados, en los que se demostró que el hecho generador estaba a cargo del agente estatal, es decir la acción u omisión, para los casos mencionados operó la falla en el servicio por omisión, pero lo decisivo no era que esta se configurara como hecho, sino como la omisión de la conducta debida que fue determinante y eficiente en la producción del hecho, y que de haberse realizado habría interrumpido el proceso causal impidiendo la producción de la lesión.

Para la CIDH el hecho generador del daño está a cargo del Estado y se le imputa, al producirse la violación de la norma internacional en caso de haber suscrito la Convención, con el consecuente deber de resarcirlo y hacer cesar las consecuencias de la violación.

La responsabilidad internacional de los Estados surge en el momento de la violación de las obligaciones generales de respetar y hacer respetar y garantizar los derechos y su respectiva protección consagrados en la convención de la Corte Interamericana de Derechos Humanos.

Es un principio de derecho internacional que el estado responde por los actos u omisiones de sus agentes realizados al amparo de su carácter oficial, aun si actúan fuera de los límites de su competencia. Además su responsabilidad cobija obligaciones de particulares en principio no atribuibles al Estado, y tiene origen esta responsabilidad en las obligaciones ERGA OMNES adquiridas por el Estado, las cuales proyectan sus efectos más allá de la relación entre sus agentes y las personas sometidas a su jurisdicción, a la adopción de medidas necesarias para asegurar la efectiva protección de los derechos humanos en las relaciones

\footnotetext{
6 República de Colombia, Consejo de Estado, Sección tercera. Sentencia de 27 de noviembre de 2002, expediente 13774, Magistrado Ponente María Elena Giraldo Gómez, actor SOCIEDAD JASSIR GÓMEZ Y CÍA LTDA

7 HENAO Juan Carlos. “El Daño, Análisis Comparativo de la responsabilidad”. Bogotá D.C: Universidad Externado de Colombia, 2001. Página 33 a 84.
} 
interindividuales, medidas que involucran los niveles legislativo, administrativo y judicial.

El carácter ERGA OMNES de las obligaciones convencionales de garantía a cargo de los Estados no implica una responsabilidad ilimitada de los estados frente a cualquier acto o hecho de los particulares, pues sus deberes de adoptar medidas de prevención y protección de los particulares en sus relaciones entre sí se encuentran condicionados al conocimiento de una situación de riesgo real e inmediato para un individuo o grupo de individuos determinado y a las posibilidades razonables de prevenir o evitar ese riesgo. Es decir, aunque un acto, omisión o hecho de un particular tenga como consecuencia jurídica la violación de determinados derechos humanos de otro particular, aquel no es automáticamente atribuible al estado, pues debe atenderse a las circunstancias particulares del caso y a la concreción de dichas obligaciones de garantía.

En conclusión para el derecho internacional el hecho dañoso atribuible al Estado no opera criterio de imputación, como se aplica en el derecho interno, pues el incumplimiento de su obligación imperativa de garantizar derechos, configura el hecho dañoso estatal.

\section{b) Daño Antijurídico}

El concepto de daño lo define la doctrina y la jurisprudencia a falta de norma colombiana que lo prescriba. Para Juan Carlos Henao el daño es "la aminoración patrimonial sufrida por la víctima"7, "el daño es requisito necesario más no necesario para que se declare la responsabilidad, debe ser probado por quien lo sufre y debe ser indemnizado plenamente".
Los elementos que se requieren para que se configure el daño son que sea cierto, presente o futuro, no eventual; particular, a las personas que solicitan reparación y que recaiga sobre un bien jurídicamente tutelado ${ }^{8}$. Para el caso de la responsabilidad del Estado, la condición personal del daño implica, que el perjuicio sea sufrido por la persona que solicita la reparación confundiéndose con el legitimado por activa para este caso la víctima del desplazamiento; el daño debe así mismo cumplir las condiciones de certeza, es decir que exista, no debe existir duda alguna acerca de su ocurrencia. ${ }^{9}$

Así mismo para que ese daño cumpla con las condiciones jurídicas para ser reparado, se requiere además de su existencia, su antijuridicidad; su imputabilidad al Estado ${ }^{10}$. Respecto del daño antijurídico el art. 90 constitucional prescribe en su primer inciso, "El Estado responderá patrimonialmente por los daños antijurídicos que le sean imputables, causados por la acción u omisión de las autoridades públicas"(...); también la doctrina y jurisprudencia acerca de la antijuridicidad del daño ha dicho, "daño antijurídico es aquel que el ciudadano no está obligado a soportar, como quiera que el ordenamiento no le impone el deber, o la carga.""11 Respecto de la imputabilidad del daño al Estado, la jurisprudencia la define por haber sido generado por su acción u omisión, cuando no se puede imputar al estado no hay reparación ${ }^{12}$, es esta la concepción integral de daño del Consejo de Estado para que sea objeto de reparación.

En el ordenamiento jurídico interno e internacional, eldañosecatalogaenmodalidades, como son el daño material: daño emergente y lucro cesante; daño inmaterial: daño moral.

8 Ibídem, pp. 93

9 Ibídem, pp. 129

10 República de Colombia, Consejo de Estado, Sección tercera. Sentencia de 26 de enero de 2007, expediente 213-01, Magistrado Ponente Ruth Stella Correa Palacio, Actor Jesús vaca y otros.

11 PENAGOS, Gustavo. “El Daño Antijurídico”. Bogotá D.C: Ediciones Doctrina y Ley Ltda, Bogotá, 1997 PP. 235-238.

12 República de Colombia, Consejo de Estado, Sección tercera. Sentencia de 26 de enero de 2007, expediente 213-01, Magistrado Ponente Ruth Stella Correa Palacio, Actor Jesús vaca y otros. 


\section{c) Nexo Causal}

El nexo causal se predica de la actuación imputable al Estado y el daño antijurídico causado, entre los cuales debe existir una relación de causalidad, es decir el daño debe ser el resultado de la actuación de un agente estatal.

Más que un vínculo material, es un vínculo jurídico entre el hecho y el daño ${ }^{13}$, que varía según la relación causal del hecho, y la modalidad en la que es producido, en caso de ser por la omisión del agente estatal, el nexo de causalidad sería entre la omisión de la conducta debida y el daño.

\subsection{ELEMENTOS DE REPARACIÓN INTEGRAL Y LA JUSTICIA TRANSICIONAL COMO DERECHOS DE LAS VÍCTIMAS}

Una vez demostrado el daño antijurídico, el hecho ilícito u omisión de la conducta debida por parte del agente estatal, el nexo causal de este con el daño demandado; las víctimas de desplazamiento tendrán el derecho a que le sean reparados integralmente los daños que tuvieron que soportar.

La reparación integral parte de la necesidad de verificar la materialización de una lesión a un bien jurídico tutelado, o de una violación a un derecho o a un interés legítimo que, consecuencialmente, implica la concreción de un daño que, igualmente, debe ser valorado como antijurídico, en la medida en que quien lo sufre no está obligado a soportarlo, como quiera que el ordenamiento jurídico no se lo impone.
El fundamento específico del principio de la reparación integral, se encuentra en el señalamiento que efectúa la propia Carta Política, en el artículo 93, en donde se reconoció de manera expresa, que todo tipo de tratado, convención o protocolo internacional que sea ratificado por Colombia, en el que se reconozcan y protejan los derechos humanos, prevalecen en el orden interno. Así las cosas, una vez se incorporan al derecho interno, a través de la celebración y ratificación, los tratados internacionales sobre derechos humanos prevalecen sobre la legislación nacional, tanto así, que tales garantías y prerrogativas no pueden ser suspendidas, ni siquiera, en vigencia de los denominados estados de excepción ${ }^{14}$.

Los estándares normativos vigentes (Ley 446 de 1998) prescribe para la valoración de los daños dentro de cualquier proceso que se adelante ante la administración de justicia, en la ponderación y determinación de aquellos irrogados a las personas y a las cosas, se atenderán los postulados de "reparación integral" y "equidad"15; También la Ley 975 de 2005 determinó el contenido y alcance del derecho a la reparación integral del perjuicio con la aplicación de medidas pecuniarias y no pecuniarias. Adicionalmente la $\mathrm{CIDH}$ ha definido cada una, criterio que ha sido acogido por el Consejo de Estado ${ }^{16}$ :

a. La restitución o restitutio in integrum, es el restablecimiento de las cosas a su estado normal o anterior a la violación, es la forma perfecta de reparación, y que sólo en la medida en que dicha restitución no resulte accesible procede acordar otras medidas reparatorias ${ }^{17}$

\footnotetext{
13 República de Colombia, Consejo de Estado, Sección tercera. Sentencia de 11 de septiembre de 1999, expediente 11764, Magistrado Carlos Betancourt Jaramillo, Actor Olimpo Arias Cedeño.

14 Determina el numeral 2 del ARTICULO 214 de la Constitución: "No podrán suspenderse los derechos humanos ni las libertades fundamentales. En todo caso se respetarán las reglas del derecho internacional humanitario...”

15 República de Colombia. Ley 446 de 1998. art. 16.

16 República de Colombia, Consejo de Estado, expediente 16996,sala de lo contencioso administrativo sección tercera. Magistrado Ponente: Dr. Enrique Gil Botero

17 Corte Interamericana de Derechos Humanos. Voto Razonado del Juez Sergio García Ramírez en la sentencia de reparaciones del Caso Bámaca Velásquez Vs Guatemala. Sentencia de 22 de febrero de 2002
} 
b. La indemnización por los perjuicios materiales sufridos por las víctimas de un caso en particular, comprende el daño material (daño emergente, lucro cesante) y el daño inmaterial ${ }^{18}$.

c. Rehabilitación, comprende la financiación de la atención médica y psicológica o siquiátrica o de los servicios sociales, jurídicos o de otra índole ${ }^{19}$.

Satisfacción, son medidas morales de carácter simbólico y colectivo, que comprende los perjuicios no materiales, como por ejemplo, el reconocimiento público del Estado de su responsabilidad, actos conmemorativos, bautizos de vías públicas, monumentos, etc $^{20}$.

d. Garantías de no repetición, son aquellas medidas idóneas, de carácter administrativo legislativo o judicial, tendientes a que las víctimas no vuelvan a ser objeto de violaciones a su dignidad, entre las cuales cabe mencionar aquellas encaminadas a disolver los grupos armados al margen de la ley, y la derogación de leyes, entre otras ${ }^{21}$.

En esa perspectiva, la reparación integral en el ámbito de los derechos humanos supone, no sólo el resarcimiento de los daños y perjuicios que se derivan, naturalmente, de una violación a las garantías de la persona, reconocidas nacional e internacionalmente, sino que también implica "la búsqueda del restablecimiento del statu quo, motivo por el cual se adoptan una serie de medidas simbólicas y conmemorativas, que propenden por la restitución del núcleo esencial del derecho o derechos infringidos, máxime si se tiene en cuenta que tales vulneraciones, tienen origen en delitos o crímenes que son tipificados como de lesa humanidad"22.
La reparación varía según daños antijurídicos derivados de violaciones a derechos humanos y los referentes al resarcimiento de daños antijurídicos emanados de lesiones a bienes o intereses jurídicos que no se refieran a derechos humanos, ya que no todo daño antijurídico reparable (resarcible), tiene fundamento en una violación o desconocimiento a un derecho humano y, por lo tanto, si bien el perjuicio padecido deberser reparadoíntegramente, dicha situación no supone la adopción de medidas de justicia restaurativa, que han sido delineadas, recientemente, en elámbito interno, por la Comisión Nacional de Reparación y Reconciliación, entre los que vale la pena destacar los siguientes:

a. Que las reparaciones sean coherentes y complementarias con los otros componentes de la justicia transicional, es decir, con el esclarecimiento de la verdad, la reconstrucción de la memoria histórica, la aplicación de la justicia y las reformas institucionales, ya que sólo de esa manera se logrará el objetivo último de las reparaciones, que incluye la dignificación de las víctimas.

b. Que las reparaciones mantengan la integralidad interna, es decir, que logren un adecuado balance entre medidas individuales y colectivas, así como entre medidas materiales y simbólicas, ya que es la única manera de asegurar que las víctimas se sientan realmente reparadas. Así mismo, el concepto de reparación integral implica que las medidas de reparación contemplen la restitución, la indemnización, la rehabilitación, la satisfacción y las garantías de no repetición.

c. Que la reparación sea adecuada, en el sentido de que las medidas de reparación deben estar acordes y ser proporcionales con [las lesiones cometidas a los derechos humanos].

\footnotetext{
18 Corte Interamericana de Derechos Humanos. Caso Aloeboetoe y otros Vs Honduras, Sentencia de Reparaciones, párr. 50.

19 Corte Interamericana de Derechos Humanos. Caso Masacre de Pueblo Bello Vs Colombia, Sentencia 31 de enero de 2006 , párr. 273.

20 Corte Interamericana de Derechos Humanos. Caso Las Palmeras. Vs. Colombia. Sentencia del 6 de diciembre de 2001 . párr 68.

21 Corte Interamericana de Derechos Humanos. Caso Las Palmeras. Vs. Colombia. Sentencia del 6 de diciembre de 2001 . párr 68.

22 Sobre el particular, se puede consultar: Estatuto de Roma (Por medio del cual se establece la Corte Penal Internacional), ratificado por Colombia, mediante la ley 742 de 2002, la cual fue objeto de revisión automática de constitucionalidad por parte de la Corte Constitucional, a través de la sentencia C-578 de 2002
} 
d. Que las reparaciones sean efectivas, es decir, que se cumplan efectivamente en la realidad.

e. Que la reparación sea proporcional al daño cometido y esté acorde con los perjuicios causados.

Regímenes aplicables a la Responsabilidad del Estado por Desplazamiento forzado.

Enlajurisprudenciacontenciosoadministrativa son aplicables en Responsabilidad extracontractual del Estado los regímenes de falla en el servicio por acción u omisión en su modalidad de probada y presunta. En cuanto a los regímenes de responsabilidad objetiva se tiene el daño especial y la teoría del riesgo excepcional. A continuación se abordan precisiones de los mismos.

\section{A. Falla del servicio}

La falla en el servicio del agente estatal tiene lugar cuando el daño se produce como consecuencia de la omisión del Estado en la prestación de los servicios de protección y vigilancia, es decir, cuando la imputación se refiere a la actuación falente o irregular de la Administración por su actuar omisivo, al no utilizar todos los medios que a su alcance tenía con conocimiento previo (previsible) para repeler, evitar o atenuar el hecho dañoso del tercero.

Para determinar si la conducta del Estado fue anómala o irregular, por acción o por omisión, frente al hecho dañoso perpetrado por el tercero debe analizarse si para la Administración y para las autoridades era previsible el hecho dañoso, este aspecto constituye uno de los puntos más importantes, para el Consejo de Estado, al analizar dentro de este régimen, "pues no es la previsión de la generalidad de los hechos (estado de anormalidad del orden público) sino de aquellas situaciones que no dejan casi margen para la duda, es decir, las que sobrepasan la situación de violencia ordinaria vivida" ${ }^{23}$

La sola circunstancia de que la víctima no haya solicitado protección previa especial no siempre será causal que permita exonerar a la administración de su deber de protección y vigilancia sino dependiendo del caso particular pueden existir otras circunstancias indicadoras que permitieran a las autoridades entender que se cometería un hecho dañoso.

Para los casos en los que se configure la omisión del agente estatal y esta determine la concreción del hecho dañoso, para que le sea imputable reparación alguna al Estado, se debe además de acreditar: a) la existencia de una obligación legal o reglamentaria a cargo de la entidad demandada de realizar la acción con la cual se habrían evitado los perjuicios; b) la omisión de poner en funcionamiento los recursos de que se dispone para el adecuado cumplimiento del deber legal, atendidas las circunstancias particulares del caso; c) un daño antijurídico, y d) la relación causal entre la omisión y el daño; omisión de la conducta debida, que de haberse realizado habría interrumpido el proceso causal impidiendo la producción de la lesión.

La conducta omisiva debe ser determinante y eficiente en la producción del hecho de tal forma que de no haberse omitido por el Estado el deber u obligación que le era exigible y previsible se habría interrumpido, con su acción, el proceso causal impidiendo la producción de la lesión ${ }^{24}$. La falla en el servicio por omisión ha sido el único régimen de responsabilidad bajo el cual el Consejo de Estado ha imputado responsabilidad estatal y por consiguiente el deber de reparar daños sufridos por población desplazada, tan solo en dos fallos.

23 República de Colombia, Consejo de Estado, Sección tercera. Sentencia de 27 de noviembre de 2002, expediente 13774, Magistrado Ponente María Elena Giraldo Gómez, actor SOCIEDAD JASSIR GÓMEZ Y CÍA LTDA

24 Sentencias proferidas por la Sección Tercera: *) el 23 de agosto de 2001. Rad. 12.975. Actor: Campo Elías Zúñiga Rivera y otros. Demandado: Nación. *) del 21 de febrero de 2002. Exp. 12.789. Actor: Argemiro de Jesús Giraldo Arias y otros. *) 2 de mayo de 2.002, Rad. 68001-23-15-000-1995-3251-01. Actor: Seguros La Andina S. A.. Demandado: Nación. 


\section{B. Riesgo excepcional}

El riesgo excepcional se materializa cuando en un actuar legítimo la autoridad coloca en riesgo a unas personas en aras de proteger a la comunidad.

Los elementos estructurales de esta forma de responsabilidad son: "Un riesgo de naturaleza excepcional para los administrados que aparece por la amenaza potencial contra los instrumentos de acción del Estado - instrumentales, humanos y de actividad - en época de desórdenes públicos provenientes y propiciados por terceros que luchan contra el mismo Estado y que se concreta con el ataque real de esos instrumentos y la consecuencia refleja en los administrados (personas o bienes), que quebranta la igualdad frente a las cargas públicas. El daño a bienes protegidos por el derecho. El nexo de causalidad, entre el daño y la conducta de riesgo creada por el Estado, con eficiencia de producir aquel. La responsabilidad patrimonial del Estado se ve comprometida cuando en ejercicio de sus actividades y obrando dentro del marco de las disposiciones legales, utiliza recursos o medios que colocan a los particulares o a sus bienes en situación de quedar expuestos a un riesgo de naturaleza excepcional. Este, dada su gravedad excede las cargas normales que deben soportar los particulares como contrapartida de las ventajas que resulta de la existencia de dicho servicio público. La Sala no desconoce que el daño en sí mismo considerado no lo produjo el Estado, sino un tercero, pero si advierte que para su producción el mencionado riesgo sí fue eficiente en el aparecimiento del mismo"25.

Sin embargo el Consejo de Estado afirma la imposibilidad jurídica de aplicar la tesis del daño especial para el desplazamiento forzado pues, "no es dable exigir de la administración lo imposible, o aquéllas cargas que superen su verdadera capacidad de acción y reacción para controlar el

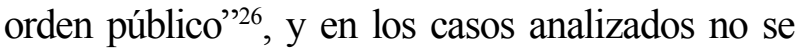

ha demostrado la capacidad del Estado para ello, la imputabilidad del daño, por parte de los actores de las acciones de reclamación.

\section{Daño Especial}

El daño especial se materializa cuando la autoridad estatal es blanco de acto de violencia, con el que se produce un daño a particulares. Es imputable al Estado pues se atacó a este y no a los ciudadanos afectados, con el consecuente deber de reparar fundado en criterios de solidaridad y equidad.

Los elementos estructurales de esta forma de responsabilidad son: "Un daño de naturaleza especial para los administrados que aparece por la realización de un hecho dañoso por parte de un tercero que luchan contra el mismo Estado y que se concreta con el ataque real la consecuencia refleja en los daños causados a los administrados. El daño a bienes protegidos por el derecho. El nexo de causalidad, entre el daño y el hecho dañoso del tercero dirigido contra el Estado ${ }^{27}$. Sin embargo para el caso del desplazamiento forzado no ha habido ningún pronunciamiento judicial que condene al Estado a reparar bajo los postulados de este régimen de responsabilidad.

\subsection{VÍA JUDICIAL Y LEGAL PARA QUE LAS VICTIMAS DE DESPLAZAMIENTO OBTENGAN UNA REPARACIÓN INTEGRAL.}

En la normatividad acerca del derecho de las víctimas a obtener una reparación integral encontramos la Ley 446 de 1998 y la Ley 795 de 2005, las cuales prescriben los requisitos de una reparación integral: restitución integral, indemnización, rehabilitación, satisfacción y

25 República de Colombia. Consejo de Estado, Sección Tercera, Sentencia de 19 de abril de 2001. Exp. 12.179 MP Dr. Mauricio Fajardo Gómez. Actor: María Margarita Cáceres Zambrano y otros.

26 República de Colombia. Consejo de Estado. Sección Tercera, MP: Dr. Ramiro Saavedra Becerra, Expediente: 10.461. Actor: Laureano Calviche y otro.

27 República de Colombia. Consejo de Estado, Sección Tercera, Sentencia de 19 de abril de 2001. Exp. 12.179 MP Dr. Mauricio Fajardo Gómez. Actor: María Margarita Cáceres Zambrano y otros. 
garantías de no repetición. Para el caso concreto del desplazamiento el año 2008 fue escenario de amplia normatividad al respecto, como la Ley 1190 y el Decreto 1290, sin embargo la reparación contenida en esta normatividad está lejos de catalogarse como una reparación integral a las víctimas del desplazamiento forzado pues se condiciona esta indemnización a que sus beneficiarios no hayan recibido como desplazados ayuda humanitaria en vivienda, al igual que no cumple con los principios de la reparación integral pues solo comprende la indemnización, que es solo un componente de ella.

Respecto a quiénes se van a reparar, el decreto establece como mecanismo para la identificación de las víctimas, los establecidos en la Red de Solidaridad Social, desconociendo de antemano la premisa de la Corte Constitucional que declara que el estatus de desplazado forzoso es una situación de hecho y no depende de la simple inscripción en una base de datos como los de Acción Social tenidos en cuenta para no otorgar reparación en casos en que las víctimas estén registradas en el SUR.

En cuanto a la vía judicial se tiene que solo hay dos reparaciones obtenidas por víctimas de desplazamiento por vía judicial impetrando acciones de grupo, en las que se demostró la responsabilidad estatal bajo el régimen de responsabilidad de falla en el servicio por omisión, lo que denota un embrionario desarrollo jurisprudencial al respecto y un reto para la actividad de los jueces administrativos, pues deben dar un marco de responsabilidad al derecho a reparaciones por parte de la universalidad de las víctimas no solo del desplazamiento.

La Corte Constitucional también se ha pronunciado para evaluar el cumplimiento que el gobierno ha realizado de lo ordenado en la Sentencia T-025 de 2004, encontrándose que no ha sido superado el estado de cosas inconstitucional en la atención humanitaria integral de las víctimas de desplazamiento, sin embargo no debe confundirse reparación integral con atención humanitaria pues esta es pos daño que se pretende con la reparación.

\section{CONCLUSIONES}

Como conclusiones de lo afirmado en el presente artículo tenemos que:

Para que se configure la responsabilidad del Estado por los daños que sufren las víctimas de desplazamiento, se deben configurar los elementos de la responsabilidad estatal en general, el hecho u omisión del agente estatal, el daño y el nexo causal entre este y el hecho generador, además de la existencia de la obligación legal quebrantada con la omisión de la conducta debida.

El fundamento principal de la responsabilidad del Estado en el desplazamiento, es la demostración de la omisión de la conducta debida, más que el nexo causal entre el hecho generador y el daño antijurídico.

El hecho generador del daño antijurídico, debe ser imputable al Estado bajo el criterio de imputación de la falla en el servicio por acción o por omisión, para que se pueda predicar deber de reparar por parte del Estado.

Los regímenes de responsabilidad objetiva: daño especial y riesgo excepcional no se han aplicado a casos de responsabilidad del Estado de reparar integralmente los daños que sufren las víctimas de desplazamiento, por la jurisprudencia del Consejo de Estado.

La reparación integral en el ámbito de los derechos humanos supone, no sólo el resarcimiento de los daños y perjuicios que se derivan, naturalmente, de una violación a las garantías de la persona, reconocidas nacional e internacionalmente, sino que también implica la búsqueda del restablecimiento del statu $q u o$, núcleo esencial del derecho o derechos infringidos, máxime si se tiene en cuenta que tales vulneraciones, tienen origen en delitos o crímenes que son tipificados como de lesa humanidad.

La jurisprudencia contencioso administrativa, debe acompasarse con los lineamientos que le son trazados por los principios y la regulación 
contenida en la Constitución Política y en el ordenamiento jurídico, como quiera que dichas disposiciones prevalecen sobre cualquier otra norma o regla de derecho vigente, en los términos del artículo 93 de la Carta Política.

Los jueces de lo contencioso administrativo y los tribunales constitucionales, a nivel interno, deben procurar el pleno y completo restablecimiento de los derechos humanos de los que tengan conocimiento, como quiera que esa es su labor, con el propósito, precisamente, de evitar que los tribunales de justicia internacional de derechos humanos, en el caso concreto de Colombia, la Corte Interamericana de Derechos Humanos, como tribunal supranacional, tenga que desplazar a la justicia interna en el cumplimiento de los citados propósitos.

El juez de lo contencioso administrativo debe asumir una posición dinámica frente a las nuevas exigencias que le traza el ordenamiento jurídico interno, así como el internacional, toda vez que, la protección de los derechos humanos se ha convertido en un aspecto de regulación positiva que ha desbordado las barreras que, tradicionalmente habían sido fijadas por los Estados en su defensa acérrima del principio de soberanía nacional.

Corresponde al operador judicial en su actividad juzgadora definir su papel en la aplicación de estos principios orientadores de la reparación; así mismo cómo debe armonizar el principio de "reparación integral" en el ámbito interno, y qué tanta influencia y fuerza vinculante proyecta en el derecho nacional este canon reconocido por el derecho internacional de los derechos humanos.

\section{BIBLIOGRAFÍA}

CORTE INTERAMERICANA DE DERECHOS HUMANOS, Sentencia caso "Masacre de pueblo Bello". Vs. Colombia.

CORTE INTERAMERICANA
DERECHOS HUMANOS, Sentencia caso "Masacre de Mapiripan". Vs. Colombia.

CORTE INTERAMERICANA DE DERECHOS HUMANOS, Sentencia caso "Masacre la Rochela". Vs. Colombia.

CORTE INTERAMERICANA DE DERECHOS HUMANOS, Sentencia caso "Masacre de Ituango". Vs. Colombia.

CORTE INTERAMERICANA DE DERECHOS HUMANOS. Voto Razonado del Juez Sergio García Ramírez en la sentencia de reparaciones del Caso Bámaca Velásquez. Sentencia de 22 de febrero de 2002.

CORTE INTERAMERICANA DE DERECHOS HUMANOS, Sentencia caso Aloeboetoe y otros, Sentencia de Reparaciones, párr. 50.

CORTE INTERAMERICANA DE DERECHOS HUMANOS, Sentencia caso Las Palmeras. Vs. Colombia. Sentencia del 6 de diciembre de 2001. párr 68.

CONSEJO DE ESTADO, Sección tercera. Sentencia 15 de agosto de 2007, expediente 401, Magistrado Ponente Ruth Stella Correa Palacio, Actor Yudy Esther Cáceres y otros.

CONSEJO DE ESTADO, Sección tercera. Sentencia de 26 de enero de 2007, expediente 213-01, Magistrado Ponente Ruth Stella Correa Palacio, Actor Jesús vaca y otros.

CONSEJO DE ESTADO, Sección tercera. Sentencia de 27 de noviembre de 2002, expediente 13774, Magistrado Ponente María Elena Giraldo Gómez, actor SOCIEDAD JASSIR GÓMEZ Y CÍA LTDA

CONSEJO DE ESTADO, Sección tercera. Sentencia del 20 de febrero de 2008. Expediente 16996. Magistrado ponente Enrique Gil Botero. Actor María Castañeda.

CONSEJO DE ESTADO. Sección Tercera. Sentencia el 23 de agosto de 2001. Rad. 12.975. Magistrado ponente Mauricio Fajardo Gómez. Actor: Campo Elías Zúñiga Rivera y 
otros. Demandado: Nación.

CONSEJO DE ESTADO. Sección Tercera. Sentencia del 21 de febrero de 2002. Exp. 12.789. Magistrado Ponente Germán Rodríguez villamizar Actor: Argemiro de Jesús Giraldo Arias y otros.

CONSEJO DE ESTADO. Sección Tercera. Magistrado Ponente Alier Hernández Enríquez Sentencia 2 de mayo de 2.002, Rad. 6800123-15-000-1995-3251-01. Actor: Seguros La Andina S.A.. Demandado: Nación.

CONSEJO DE ESTADO. Sección tercera. Expediente: 10.461. Magistrado Ponente Ramiro Saavedra Becerra. Actor: Laureano Calviche y otro.

CONSEJO DE ESTADO, Sección Tercera, Sentencia de 19 de abril de 2001. Exp. 12.179 Magistrado Ponente Mauricio Fajardo Gómez. Actor: María Margarita Cáceres Zambrano y otros.

CONSEJO DE ESTADO, Sección tercera. Sentencia de 11 de septiembre de 1999, expediente 11764, Magistrado Ponente Carlos Betancourt Jaramillo, Actor Olimpo Arias Cedeño.

JUAN CARLOS HENAO, El Daño, Análisis Comparativo de la responsabilidad extracontractual del Estado en derecho colombiano y francés. Bogotá: Universidad Externado de Colombia. 1998.

PENAGOS, Gustavo. El Daño Antijurídico. Aplicación del principio iura novit curia. Bogotá. Ediciones Librería Doctrina y ley. 1997 